\title{
Letramento Digital, uma Análise dos Discentes Bolsistas do PIBID-UFRA do Curso de Licenciatura em Computação.
}

\author{
Tiago L. de Souza ${ }^{1}$, Larissa Sato Elisário ${ }^{1}$ \\ ${ }^{1}$ Instituto Ciberespacial (ICIBE) - Universidade Federal Rural da Amazônia (UFRA) \\ Cep. 66077-901 - Belém - PA - Brasil \\ tiago.licomp@gmail.com, larisato@gmail.com
}

\begin{abstract}
This article is about a research on electronic literacy made with scholarship recipients of the Programa Institucional de Bolsa de Iniciação à Docência (PIBID) of the Universidade Federal Rural da Amazônia, Belém campus, Computing course (Teaching Modality). The research was carried out with 27 students from a total of 63 of the program and has as one of the objectives to analyse the knowledge and the profile of the scholarship holders against the electronic and digital literacy. As the main contribution of this research is made a relation between the knowledge and profile of these fellows with the actions that they execute in PIBID and the results show that the application of the electronic literacies is reasonable in the program.
\end{abstract}

Resumo. Este artigo trata de uma pesquisa sobre letramentos eletrônicos feita com bolsistas do Programa Institucional de Bolsa de Iniciação à Docência (PIBID) da Universidade Federal Rural da Amazônia (UFRA), campus Belém, curso de Computação (modalidade Licenciatura). A pesquisa foi feita com 27 bolsistas do programa, de um total de 63, e tem como objetivo analisar o conhecimento e o perfil dos bolsistas frente aos letramentos eletrônicos e digitais. Como principal contribuição desta pesquisa foi feita uma relação entre o conhecimento e o perfil desses bolsistas com as ações executadas no PIBID e os resultados mostram que a aplicação dos letramentos eletrônicos é razoável no programa.

\section{Introdução}

Várias questões sobre a presença das Tecnologias de Informação e Comunicação (TIC) no cotidiano são discutidas atualmente e uma delas é como essas tecnologias e o conhecimento sobre elas estão presentes no ambiente escolar através da inclusão e letramento digital. Mark Warschauer é um dos estudiosos que relaciona a Tecnologia

\footnotetext{
1 Tiago Souza: Graduando em Licenciatura em Computação pela Universidade Federal da Amazônia (UFRA) e ex-bolsista do Programa Institucional de Bolsa de Iniciação à Docência (PIBID).

Larissa Elisiário: Professora da Universidade Federal da Amazônia (UFRA) e coordenadora geral do Programa Institucional de Bolsa de Iniciação à Docência (PIBID) na UFRA.
} 
digital e a inclusão social de várias perspectivas e aborda alguns conceitos que envolvem questões sobre esses dois temas. Um dos conceitos abordados por Warschauer são os letramentos eletrônicos e as definições desse autor sobre esses letramentos serão usadas como base para esta pesquisa.

Além disso, esta pesquisa associa a importância dos letramentos eletrônicos à escola e ao papel dos bolsistas do Programa Institucional de Bolsa de Iniciação à Docência (PIBID) da Universidade Federal Rural da Amazônia (UFRA) do curso de graduação em Licenciatura em computação para fazer uma análise do perfil desses discentes, dos conhecimentos deles em relação a esses letramentos e, como principal contribuição desta pesquisa, saber se estes estão presentes nas ações que são exercidas no programa.

\section{Considerações Sobre o PIBID}

O Programa Institucional de Bolsa de Iniciação à Docência é um programa da Coordenação de Aperfeiçoamento de Pessoal de Nível Superior (CAPES) executado na UFRA em diferentes campi, entre eles o campus Belém-PA onde ocorreu está pesquisa. O programa é aplicado no curso de Licenciatura em Computação e já existe desde 2012 na instituição, tendo como principal objetivo inserir discentes de licenciatura em escolas públicas antes de sua formação para que tenham experiência da prática docente e contato com metodologias e tecnologias de ambientes escolares.

O PIBID-UFRA está presente unicamente no curso de Licenciatura em Computação e é um programa que, segundo o item 4.3 do Projeto Institucional PIBID/UFRA (2013), "iniciou sua primeira proposta de PIBID principalmente a partir das demandas de inclusão (social, digital e de participação democrática nas decisões de sua comunidade) apresentadas pelas escolas visitadas." A partir disso, o compromisso com a comunidade escolar é principalmente de ser um programa de inclusão, principalmente digital. Além disso, PIBID/UFRA(2013):

Os subprojetos propostos permeiam o uso dos conceitos "competência para a informação" e "aprendizagem para a vida", que devem nortear as ações nos subprojetos, contemplando as competências para buscar, analisar e usar informações para alcançar objetivos pessoais, sociais, educacionais e de trabalho, enfim, para a inclusão social.

A partir desse cenário, buscou-se analisar as questões dos Letramentos eletrônicos já que para existir uma inclusão digital e social os letramentos eletrônicos na era da informação são muito necessários no combate à desigualdade social e digital através do ambiente escolar.

Como aborda Velloso (2011) "um importante papel reservado para as escolas é o de propiciar descobertas para novos usos pedagógicos da tecnologia, tendo em vista a 
VI Congresso Brasileiro de Informática na Educação (CBIE 2017)

Anais dos Workshops do VI Congresso Brasileiro de Informática na Educação (WCBIE 2017)

formação para a cidadania." em concordância com o projeto institucional do PIBID-UFRA (2013) que diz que:

a discussão deve ser permanentemente estimulada entre os participantes dos projetos na UFRA e os supervisores e a comunidade da escola acerca dos Direitos Universais do cidadão, que são o acesso à informação nos meios digitais como uma questão de cidadania e um direito universal básico.

É nesse contexto, então, que encontrou-se a necessidade de pesquisar a presença dos letramentos eletrônicos no programa através dos bolsistas e das ações que são executadas por eles.

\section{Os Letramentos Eletrônicos}

Nesta seção serão abordados breves conceitos sobre cada um dos letramentos que serão usados na pesquisa e que variam do conceito de Letramentos Eletrônicos, pois esta pesquisa é pautada em investigar os bolsistas do PIBID-UFRA de acordo com os letramentos eletrônicos ou letramento digital. De acordo com Warschauer (2006, pg. 154), o Letramento Eletrônico:

É uma expressão geral, que abarca diversos outros letramentos genéricos da era da informação, incluindo aqueles por via do computador, e os letramentos informacional, multimídia e comunicacionais mediados por computador.

O letramento digital pode ser facilmente confundido com o letramento eletrônico. As bases das definições para ambos são um pouco complexas e há uma variedade de significados. Para partir de uma perspectiva mais ampla, cito Velloso e Marinho (2011) que falam um pouco do conceito mais abrangente de letramento quando dizem que "as diversas categorias presentes no termo letramento [...] nem sempre estão associados ao meio digital. Sugere-se que se pluralize a palavra letramento para letramentos múltiplos ou multiletramentos." Freitas (2010) traz uma abordagem mais específica quando diz que compreende:

letramento digital como o conjunto de competências necessárias para que um indivíduo entenda e use a informação de maneira crítica e estratégica, em formatos múltiplos, vinda de variadas fontes e apresentada por meio do computador-internet, sendo capaz de atingir seus objetivos, muitas vezes compartilhados social e culturalmente.

Já Magda (2002) conceitua letramento digital em um contexto mais relacionado à mudança na escrita:

Em síntese, a tela, como novo espaço de escrita, traz significativas mudanças nas formas de interação entre escritor e leitor, entre escritor e texto, entre leitor e texto e até mesmo, mais amplamente, entre o ser 
humano e o conhecimento [...] a hipótese é de que essas mudanças tenham consequências sociais, cognitivas e discursivas, e estejam, assim, configurando um letramento digital, isto é, um certo estado ou condição que adquirem os que se apropriam da nova tecnologia digital e exercem práticas de leitura e de escrita na tela.

Assim ambos os conceitos, letramento digital e eletrônico, podem aparecer neste texto para abordar uma forma mais geral dos letramentos essenciais hoje em uma sociedade digital e ter uma visão mais ampla nesta pesquisa. Esses letramentos eletrônicos serão apresentados a seguir.

\subsection{O Letramento por Meio do Computador}

Segundo Warschauer (2006), o letramento por meio do computador nas suas primeiras aplicações tinha um foco muito voltado ao uso do computador em si e ao seu acesso físico e limitava uma relação com conteúdos e propósitos mais significativos para o aprendizado do aluno em relação ao uso dessa ferramenta de forma mais abrangente.

\subsection{O Letramento Informacional}

Já o letramento informacional não está apenas ligado às tecnologias digitais, mas a todas as outras que envolvem a era da informação. Este letramento está mais conectado ao pensamento crítico e analítico que um indivíduo precisa ter ao lidar com uma gama enorme de informações no mundo da internet. Segundo Warschauer (2006, pg.158) "Em tais circunstâncias, faz pouco sentido discutir o letramento crítico como um construto separado ou especial; ao contrário, o letramento crítico é um elemento essencial de leitura na era on-line".

\subsection{O Letramento Multimídia}

O letramento multimídia envolve uma questão mais voltada à representação da linguagem ao longo do tempo e como transformamos a escrita em conteúdos com imagem e som, ou seja, audiovisual. Como a escrita foi elitizada por muito tempo, os conteúdos multimídia se tornaram uma forma de comunicação mais acessível a pessoas mais pobres, apesar de a produção multimídia sofisticada ainda ser dominada por classes mais ricas, pois os equipamentos e softwares para esse tipo de produção ainda é muito caro. Assim destaca-se a importância de haver cada vez mais produtores desses conteúdos em escolas, principalmente em escolas públicas e periféricas para que haja mais representação de conteúdos audiovisuais de qualidade feito por pessoas com menos acesso a esse meio. Warschauer (2006) também aborda que:

O avanço da multimídia deve proporcionar uma oportunidade importante para equilibrar o jogo do letramento, restaurando o status de formas mais naturais de comunicação audiovisual, que, de alguma maneira, são mais amplamente acessíveis. 


\subsection{O Letramento Comunicacional}

O último letramento a ser abordado é o comunicacional mediado por computador. Warschauer (2006) afirma que este, de todos os letramentos citados, é o menos estudado e abordado por estudiosos de letramento eletrônico. Muitas vezes a comunicação por meio do computador pode ser confundida como algo simples e fácil por ser uma atividade que para os jovens, por exemplo, pode ser facilmente adquirida quando passam algumas horas frente a um chat ou bate papo, mas quando se fala de pessoas mais velhas ou que têm pouca familiaridade com recursos básicos do computador, essa se torna uma tarefa mais difícil. A comunicação mais formal, como a acadêmica, por exemplo, não se aprende de forma tão natural.

Por fim, esses letramentos contemplam apenas uma parte do que seriam os letramentos que um indivíduo pode aprender ao longo que interage com o mundo digital, mas há outros conhecimentos e letramentos relacionados com os que já foram citados. Conforme as tecnologias vão se tornando mais avançadas e outras mais defasadas, esses letramentos são ressignificados e por isso podem apresentar níveis de relevância diferentes dependendo de cada contexto.

\section{Metodologia}

A pesquisa foi feita através de um formulário web no Google Drive com 31 perguntas relacionadas aos letramentos que envolvem o conceito mais amplo de letramentos eletrônicos citados e conceituados anteriormente. O formulário foi compartilhado através da rede social Whatsapp por se tratar de uma ferramenta de comunicação mais ágil e de fácil visualização. Assim, um número total de 63 bolsistas ativos no PIBID do curso de Licenciatura em Computação da UFRA, campus Belém, receberam o link para preencher.

Escolheu-se analisar apenas os bolsistas ativos para observar a situação mais atual deles e do programa em relação aos letramentos eletrônicos. Desta forma os dados podem ser analisados de forma mais concreta e clara já que os supervisores, coordenadores e as escolas mudam a cada edital.

O formulário foi dividido em três seções de perguntas objetivas e descritivas. A primeira seção continha perguntas referentes ao conhecimento dos bolsistas em relação aos letramentos eletrônicos, a segunda tinha questões sobre o uso dos letramentos no cotidiano deles e a última seção indagava sobre a aplicação desses letramentos nas ações e projetos que esse bolsista executa com os alunos nas escolas do PIBID. Cada seção tinha pelo menos uma pergunta que era relacionada a letramento mediado pelo computador, informacional, multimídia e comunicacional mediado pelo computador. No ínicio do formulário, antes das seções citadas, haviam perguntas de cunho pessoal para identificação dos bolsistas, informações básicas em relação ao programa PIBID, 
como a escola onde atuam, e depois perguntas que identificavam o acesso físico deles em relação à tecnologia digital.

O objetivo de dividir o formulário desta forma era poder identificar os letramentos eletrônicos no perfil dos bolsistas, analisar o conhecimento que eles possuem desses conceitos e também nas ações que executam no programa. Em seguida serão analisados os resultados das perguntas de acordo com a perspectiva de cada letramento eletrônico citado.

\section{Resultados e Discussão}

Com essa pesquisa pretende-se responder três questionamentos: 1 - Qual o perfil dos bolsistas do PIBID-UFRA frente ao letramento digital? 2- Que conhecimento os bolsistas têm em relação aos conceitos que envolvem os letramentos eletrônicos? 3Os bolsistas aplicam ações que envolvem os letramentos eletrônicos em seus projetos nas escolas? O objetivo principal é responder à terceira pergunta, porém percebeu-se a necessidade de analisar o quanto os bolsistas sabem sobre esse conteúdo e se eles estão presentes no cotidiano dos discentes para ter um resultado mais pautado na bagagem que esses trazem para sala de aula e para os seus projetos no programa.

Dos 63 discentes ativos no programa do PIBID-UFRA, campus Belém, 27 (42\%) responderam ao questionário da pesquisa. As próximas análises serão separadas conforme os questionamentos citados acima na tentativa de respondê-los.

\section{- Que conhecimento os bolsistas têm em relação aos conceitos que envolvem os letramentos eletrônicos?}

Como todos os questionamentos que seguem neste tópico, para responder à dúvida acima foram feitas seis perguntas e pelo menos uma delas envolvia um dos letramentos citados no tópico de letramentos eletrônicos. A primeira delas perguntou diretamente se os bolsistas possuíam alguma noção do que seriam letramentos eletrônicos. 45\% dos bolsistas disseram ter uma noção do que seriam estes letramentos e mais da metade disse que não tinha noção desse termo. Dos 45\% (12 bolsistas), apenas 8 (30\%) deles disseram ter estudado ou lido algo sobre pelo menos um dos letramentos eletrônicos citados em uma lista, onde as opções eram: letramento mediado pelo computador, digital, informacional, multimídia e mediado pelo computador. E dos 55\% que afirmaram não conhecer letramentos eletrônicos, todos marcaram que não conheciam nenhum dos letramentos citados. Isso comprova que dos 27 bolsistas, apenas 8 (30\%) tem alguma noção e estudou ou leu algo sobre letramentos eletrônicos e $70 \%$ não.

Em outras perguntas foi possível analisar individualmente o conhecimento dos bolsistas sobre cada letramento eletrônico. O primeiro foi o letramento por meio do computador. Este foi o letramento que os bolsistas (26\%) mais ouviram falar e estudaram algo sobre e quando perguntados sobre o valor que este letramento pode 
trazer para a vida de um indivíduo, a maioria das opiniões dos bolsistas converge que a educação e o aprendizado do indivíduo ou aluno é o principal benefício que alguém adquire através desse letramento, e isso envolve o pensamento crítico, a inclusão na educação e facilitação do aprendizado por meio dos recursos computacionais.

Já o letramento informacional é de conhecimento de apenas 7,4\% dos discentes, mas foi solicitado que os $100 \%$ selecionassem palavras dentro de uma lista disponível que mais se aproximasse do significado deste letramento para eles. Na lista estavam presentes as seguintes palavras: Credibilidade da informação, Confiabilidade, Avaliação dos dados, Alfabetização, Informação incorreta, Hiperlink, Internet, TICs, Nenhuma das frases. $41 \%$ (a maior porcentagem) de todos os bolsistas acha que a "Credibilidade da informação" era a frase que mais definia o significado desse letramento seguido por "Tecnologias da informação e Comunicação (TICs)". Os 7,4\% dos bolsistas que já estudou algo sobre este letramento, definiu-o com "Credibilidade da informação".

Quanto ao letramento multimídia, a maioria dos discentes $(70,4 \%)$ atribuíram a nota cinco (muito importante) para uma escala de 1 à 5 , quando perguntados sobre a importância que o ensino de produção multimídia e audiovisual têm nas escolas de ensino médio e fundamental. Grande parte deles atribuiu essa importância à nova realidade em rede que os alunos estão inseridos e este letramento os ajudaria a ser incluídos nesse meio e a aprender novas habilidades que ajudariam no seu aprendizado na escola.

E quando perguntados se acreditavam que hoje qualquer pessoa consegue se comunicar facilmente de forma efetiva na internet em qualquer plataforma de comunicação, 63\% (17 bolsistas) marcou que NÃO e 37\% (10 bolsistas) que SIM. Este resultado reflete o que comentou Warschauer (2006) quando diz que grande parte das pessoas atribui uma certa facilidade para a comunicação online, pois na maioria das vezes se trata de ambientes como chats e bate-papos mais intuitivos para jovens, mas não para pessoas mais velhas. O mesmo ocorre quando não se trata de comunicação informal e sim de uma comunicação mais formal e rebuscada, como ambientes acadêmicos, por exemplo.

Portanto, apesar dos bolsistas declararem em sua maioria que não possuem nenhuma noção de conhecimentos eletrônicos e nunca terem estudado diretamente algo sobre, as respostas em relação aos conhecimentos específicos de cada letramento se mostrou bastante satisfatória segundo aos conceitos apresentados anteriormente, pois todos conseguiram demonstrar um pouco do significado e aplicação de cada um dos letramentos na sociedade hoje.

\section{- Qual o perfil dos bolsistas do PIBID-UFRA frente ao letramento digital?}

As perguntas aqui estavam mais relacionadas à aplicação dos conceitos de letramento eletrônico no cotidiano dos bolsistas para saber como estes estão presentes na relação 
deles com as Tecnologias de comunicação e informação. As perguntas foram feitas de modo que não citam diretamente cada letramento, mas aspectos para identificar a aplicação no cotidiano deles.

Um dos pontos avaliados foi a questão do acesso físico. Pelo menos $90 \%$ tem acesso a um computador (notebook ou desktop) e um celular em casa. Todos têm acesso a pelo menos uma tecnologia digital de acesso à internet (Notebook, Tablet, celular, etc) e mais de $82 \%$ possuem acesso à internet banda larga em casa, seja no seu computador desktop, Netbook, tablet ou celular, sendo que dos 27 bolsistas, 3 apenas não possuem telefone celular e 3 não possuem computador.

Também houveram perguntas que questionavam se alguma atividade do cotidiano dos bolsistas foi potencializada graças ao uso do computador. Um dos bolsistas citou cursos a distância ao dizer que, "cursos gratuitos a distância foi importante por que nem sempre tenho disponibilidade ou recursos financeiros para fazer os cursos e através do computador e até mesmo do celular me proporciona aprender e ter acesso ao conteúdo que são disponibilizados para a conclusão do curso.”, já outro bolsista destacou a "Produção de trabalhos, textos, redações.", além deste último, cerca de $22 \%$ dos bolsistas citou a escrita ou produção de trabalhos e pesquisas como atividade que foi potencializada pelo computador no seu cotidiano. Este resultado está relacionado com o exemplo demonstrado Warschauer (2006) quando cita que a potencialização da escrita pode estar relacionada com a produtividade de um indivíduo e o uso do computador para escrever.

Além disso, mais de $80 \%$ dos bolsistas declarou que a credibilidade de uma informação é muito importante na internet, mas quando questionados sobre a frequência com que pesquisam a fonte e a credibilidade de uma pesquisa feita na rede, apenas $30 \%$ declarou fazer isso com muita frequência. Segundo Warschauer (2006) no letramento informacional o pensamento crítico está relacionado com a preocupação que o indivíduo deveria ter ao se deparar com qualquer informação encontrada e neste caso houve divergência entre acreditar em uma informação e realmente pesquisar sua integridade e fontes.

Por último, os bolsistas declaram, em uma escala de 1 a 5 , onde 1 é nunca e 5 é sempre, sobre a frequência com que usam softwares para produção de conteúdo audiovisual e multimídia. A maioria dos bolsistas (40\%) marcou a escala 5, que sempre usam softwares de edição de conteúdo audiovisual e multimídia e $24 \%$ declarou que quase sempre e $28 \%$ às vezes os usa, os outros $8 \%$ somam os bolsistas que usam muito pouco esses softwares.

Portanto, grande parte dos bolsistas se demonstrou mais apto aos letramentos eletrônicos. A maioria conseguiu identificar potencialidade no computador para tarefas do cotidiano demonstrando que há letramento por meio do computador. Já quando se fala do informacional, a porcentagem de pessoas que procura apurar informações com 
certa frequência é bem baixa, ou seja, não alimentam muito seu potencial crítico na leitura online. Quanto ao comunicacional a maioria não tem problemas para se comunicar na rede e grande parte usa recursos para criar conteúdo multimídia.

\section{- Os bolsistas aplicam ações que envolvem os letramentos eletrônicos em seus projetos nas escolas?}

A primeira pergunta que compôs esta seção da pesquisa questionava o seguinte assunto: você (bolsista) acredita que o Letramento por meio do computador no PIBID-UFRA existe por meios das ações do programa? Segundo as respostas, mais da metade dos bolsistas $(58,3 \%)$ acredita que o letramento por meio do computador existe no programa, e acredita que há objetivos, propósito claro e tarefas significativas com os alunos. $25 \%$ declarou que consegue identificar a existência deste letramento nas ações do programa, mas sem objetivo, propósito e tarefas significativas. $16,7 \%$ declarou que não consegue identificar o letramento por meio do computador no programa em nenhuma de suas ações nas escolas.

Os bolsistas que responderam que não existem letramentos nas ações do programa, justificaram suas respostas dizendo que não conseguem identificar ações com esse tema nas suas escolas e no programa como um todo. Uma bolsista citou que "não existe (letramento eletrônico) no programa ainda, porque para fundamentá-lo seria necessário adotar uma teoria da abordagem, que não se resumisse à transmissão de conteúdos ou jogos com erros e acertos e sim uma ação integrada, com conhecimentos pedagógicos e técnicas de coletas de dados mais abrangentes." Já os que disseram que existe este letramento nas ações do programa, declararam que o ensino da informática gera automaticamente o letramento eletrônico e suporte para a escrita e leitura digital.

Mesmo que a maioria dos bolsistas tenha declarado que consegue identificar os letramentos eletrônicos nos projetos do PIBID-UFRA, os resultados sobre a aplicação desses letramentos nas ações não reflete no programa como um todo, mas em pequena parte das ações. Apenas 22,2\% dos bolsistas declarou que já avaliou a leitura crítica online dos seus alunos, o que está diretamente relacionado ao letramento informacional, mais da metade $(55,6 \%)$ disse que nunca realizou ações com os alunos onde o foco fosse a produção de conteúdo audiovisual ou multimídia e apenas $25,9 \%$ se envolveu em projetos onde a comunicação dos alunos na internet em chats, e-mail, e outras plataformas de comunicação era um dos focos principais.

Outro aspecto avaliado foi a presença dos laboratórios de informática presentes nessas escolas, e mesmo o PIBID funcionando através de um curso de licenciatura em computação, 33,3\% dos bolsistas declarou trabalhar em uma escola que não possui laboratório de informática funcionando. Por essa limitação, eles compõem grande parte da porcentagem de bolsistas que não conseguiu avaliar a leitura crítica online dos seus alunos, nem trabalhar com recursos multimídia e audiovisual, e também nunca 
trabalharam a comunicação online dos alunos nessa escola, ou seja, a maioria dos letramentos eletrônicos não foram aplicados pelos bolsistas na escola por limitação física dos recursos necessários. Porém, $40 \%$ do total de bolsistas que fazem parte do grupo que não tem laboratório nesta escola, conseguiu verificar a leitura crítica online dos seus alunos mesmo sem o laboratório, mas não declararam qual foi a metodologia usada.

\section{Conclusões}

Portanto, mesmo que a maioria dos bolsistas tenha declarado que não tinham noção ou estudo sobre letramentos eletrônicos ou digitais, grande parte destes têm um conhecimento necessário para identificar onde possam estar presentes e até aplicá-los em suas ações no PIBID-UFRA. Ao avaliar seu perfil diante dos seus próprios letramentos, também se demonstraram aptos a desenvolvê-los em tarefas do seu cotidiano. Porém, ao analisar como os bolsistas aplicam esse conhecimento no programa em questão, grande parte declarou que esses letramentos não estão presentes em todas as ações ou na maioria delas, mas em parte significativa para um programa que trabalha com várias vertentes da informática e da computação.

A principal contribuição da pesquisa é servir como uma das bases para tomar futuras decisões em relação a projetos que envolvam a inclusão e letramento digital dos alunos nas escolas públicas através do PIBID-UFRA, pois muitas ações são executadas sem verificar o conhecimento dos bolsistas em relação ao conteúdo que será abordado, o background que já possuem e como isso já foi ou é aplicado no programa recentemente.

Além disso, pesquisas futuras podem analisar o nível do letramento digital dos alunos das escolas onde o PIBID-UFRA está presente e traçar o perfil desses alunos frente a inclusão digital e comparar com os resultados dessa pesquisa.

\section{Referências}

Freitas, M. T. (2010), "Letramento Digital E Formação De Professores”, Educação Em Revista, Belo Horizonte, V.26. N.03, P.335-352, Dez.

Magda S. (2017), "Novas Práticas De Leitura E Escrita: Letramento Na Cibercultura" Educ. Soc., Campinas, Vol. 23, N. 81, P. 143-160, Dez. 2002. Ufra (2013), Projeto Institucional (Conforme Item 4.3 Do Edital No 61/2013) Pibid/Ufra.

Velloso, M. J. M., Marinho S. P. P. (2011), "Letramento Digital Via Web 2.0: Uso Do Site Toondoo Em Sala De Aula", Anais Do XXII Sbie - XVII WIE Aracaju, Novembro.

Warschauer, Mark. (2006), Tecnologia E Inclusão Digital: A Exclusão Digital Em Debate; Tradução Carlos Szlak. - São Paulo: Editora Senac São Paulo. 